\title{
Two scientists in a hurry
}

\author{
When going to the annual meeting got tough, \\ These ambitious students got going $-6,000$ miles by car
}

C.A. Hewett and C.S. Pai didn't plan to drive 3,000 miles from San Diego to Boston to attend last year's Fall Meeting of the MRS. But they couldn't afford to get there any other way, and they couldn't afford to miss the meeting, so they drove. And since they also couldn't afford wasted time away from their laboratories, they drove it straight through.

Hewett and Pai are graduate students at the University of California at San Diego, working toward Ph.D.s in electrical engineering. Their mentor, Professor S.S. Lau, is a long-time member and supporter of the MRS.

\section{Plans Go Awry}

"Originally, it started out that there were three or four of us going," says Hewett. "Then one of us couldn't go, and then another one, who works for Hughes Research, was flown to Boston to meet with a supplier-so it was just the two of us."

The young scientists never considered canceling their plans. Not only is the fall conference of the MRS "one of the most important meetings in our area of research," as Pai says, but both Hewett and Pai were to deliver papers before MRS symposia, making the conclave among their first opportunities to address as colleagues other members of the materials community.

Hewett was contributing a paper to the symposium on ion implantation and ion beam processing of materials, and Pai to the symposium on thin films and interfaces.

\section{Speeding in Texas}

The pair left San Diego Thursday at noon for a conference due to begin Sunday. They took no breaks, taking turns sleeping in the back seat while the other drove. They reached Oklahoma City in only 24 hours. Their single delay was a speeding ticket Pai picked

\section{Not only were the grad students \\ Anxious to attend a premier conference- Each of them was going to deliver a paper}

up in Texas. "I did it, too," Hewett confesses, "but I was lucky enough I didn't get caught."

Actually, Hewett and Pai didn't drive straight to Boston: In New York, they took a side trip to JFK International Airport to pick up a friend, Illka Suni of Finland, a former Caltech student returning to the United States to attend the MRS meeting. Despite the extra driving, however, Hewett and Pai managed to

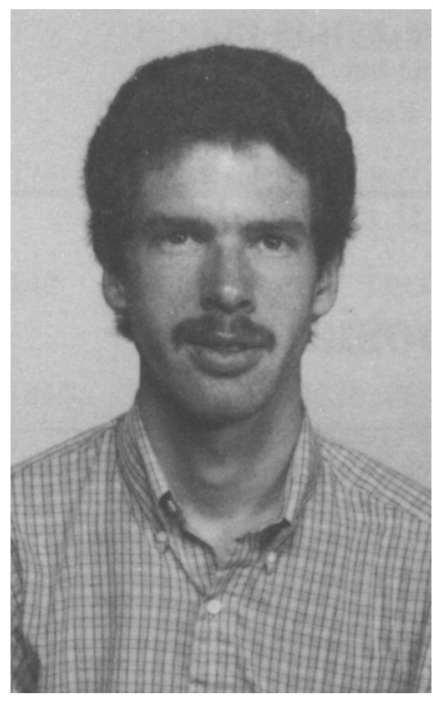

C.A. HEWETT

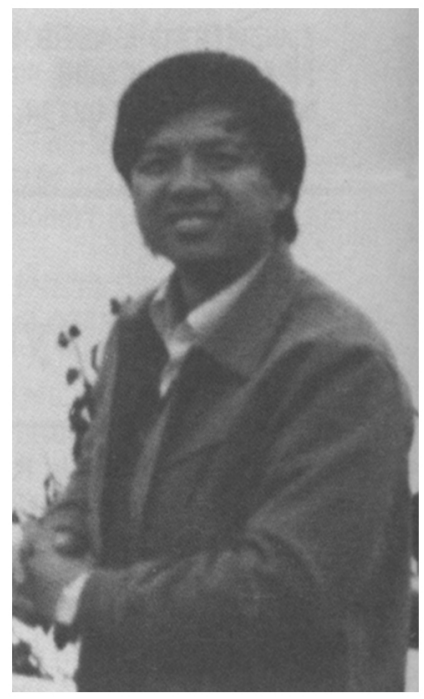

C.S. PAI arrive in Boston Saturday night, in plenty of time for the meeting's opening sessions.

\section{Going Home Took Longer}

The graduate students stayed in Boston through Thursday, having participated fully in their respective symposia and attending as many other sessions as they found time for. Then they drove to Hewett's home in Rochester, New York, for an overnight rest. Next they visited the Cornell University laboratory of Professor J.W. Mayer, a recipient of the MRS's Von Hippel Award under whom Hewlett had studied as an undergraduate in materials science. After another side trip to see Niagara Falls, Hewlett and Pai drove straight home to San Diego, arriving on Tuesday morning, some 13 days after they had departed.

\section{Next Time: A Slow Boat}

School was, of course, in session, and upon their return the students went directly to their lab, where, Hewett says, "I fell asleep-for about a day and a half." Pai adds it took him "a couple of days to recover" from an odyssey that had taken them over 6,000 miles through nearly a score of states.

They say they are planning to return to Boston for this year's Annual Meeting. But this time they won't drive. Says Hewett, "This time we thought we'd find a yacht and sail." 